\title{
LIGATION OF THE PATENT DUCTUS ARTERIOSUS
}

\author{
BY \\ TERENCE EAST \\ From the Cardiological Department, Kings College Hospital \\ Received February 23, 1945
}

This operation is now being performed to cure patients who have become infected, but also it may be done to remedy a congenital defect, which very considerably reduces the prospects of longevity, and is as well the source of several serious disadvantages.

This is an account of the experience provided by thirteen cases, considered from the medical point of view. All the operations were done by Mr. John B. Hunter, F.R.C.S., and Dr. Nosworthy gave the anæsthetic.

\section{Diagnosis AND Prognosis}

Diagnosis presented no difficulty: the typical murmur, best heard in the second left intercostal space, starting just after the first sound and persisting into diastole (with the exception of one case where it is doubtful whether it would be heard beyond the second sound), was present in all. This applies to two other cases seen during the same period, who declined operation. Its hollow whizzing character resembles nothing else to my ear. Is not " machinery murmur" a bad expression? I cannot think of any machine causing such a sound. In most a thrill was palpable as well. Sometimes there was a systolic pulsation, and as a rule the pulmonary second sound was loud and the closure palpable. The pulmonary artery was never large enough to cause dullness. The possible presence of another congenital defect, in particular pulmonary stenosis, was always considered but was never suspected. A normal cardiogram, and the absence of its peculiar murmur lower down should exclude pulmonary stenosis. Obviously, if this were present, ligation of the ductus would be undesirable.

All the cardiograms were within normal limits.

Enlargement of the pulmonary artery in the skiagram may be quite conspicuous, but in this series of thirteen cases it is clear from the outlines shown in the figure that nothing very striking may be noted. In Case 4 the pulmonary artery was largest, and that has a flat curve.

Enlargement of the heart was present only in Case 3 and perhaps in Case 2. But in this series the disease was in its early stage, and failure had in no case come on. The blood pressure readings showed no constant abnormality, but an average figure of 120/70 indicated a slightly increased pulse pressure. In some the diastolic pressure tended to be low.

Physical examination before operation gave no reliable information as to the size and shape of the ductus.

Probably in most cases, until well into adult life, a patent ductus arteriosus may interfere but little with activities. But such a lesion as this is almost certain to be recognized early in life, and in many instances restrictions that are probably unnecessary are imposed. The result is that the patient is well aware that there is something wrong with him, and may become unduly heart-conscious and even neurotic. He will certainly miss a great deal of the best that youth can give.

Later on more serious considerations arise. Employment in many walks of life will be hard to obtain. The Services, civil and military, will be closed to him; banks and many firms will not employ him because he is ineligible for staff schemes and pension funds. Life assurance will be denied him. Strenuous occupations will be unwise; a woman may be 


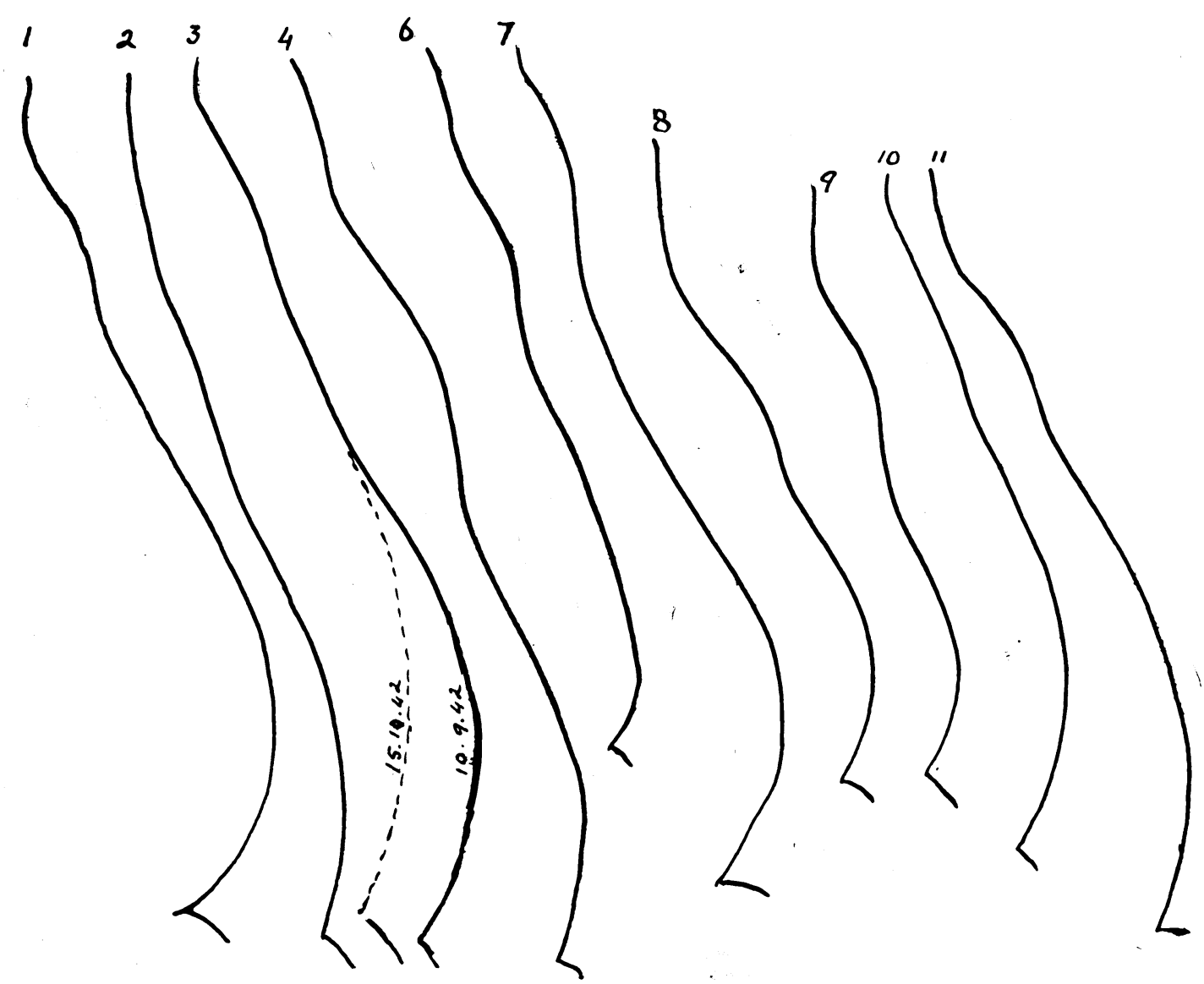

FIG. 1.-Outlines of the left border of the hearts, before and after operation, in patent ductus arteriosus. The numbers correspond with those of the cases.

advised against marriage and certainly against pregnancy, although she would probably accomplish this well enough.

Ultimate Prognosis. The danger of infection in these patients is considerable. Although for the most part they seem to reach the twenties without disability, they are rarely seen in middle age. I cannot recollect having seen one over the age of forty. Heart failure no doubt accounts for the early death of many.

\section{Choice of Operation and Results}

The experience of this small series makes one conclude that ligation of the patent ductus arteriosus by a surgeon skilled in thoracic surgery, aided by an anæsthetist who has practised the technique that this work requires, is not a dangerous procedure. The small pneumothorax or hydrothorax, which sometimes appeared, very soon cleared up with the help of breathing exercises. In no case was there any anxiety about the patient after the operation. Breathing exercises were always given on or soon after the third day. Unquestionably the children were least affected, and tolerated the operation very well.

Age for Operation. Any time in childhood, as soon after the sixth year as possible for preference, seems to be the best. I believe that my colleague, Mr. Hunter, who is describing these cases elsewhere from the surgical point of view, is of opinion that for technical reasons the operation is easier in children. Certainly it would be an advantage to cure this defect as soon as possible in order that its undesirable effects on mental and physical development may be eliminated while the child is growing. It is obviously a good thing to have as normal a childhood as possible. 
In all these patients the signs of the patent ductus disappeared (with one exception, for reasons given). It was the practice of Mr. Hunter, before ligation, to press on the ductus with his finger and note the disappearance of the thrill. This was always there, even if it could not be felt on the chest wall.

The contour of the heart showed very little change in subsequent skiagrams, except in Cases 2 and 3 where the ventricles decreased a little in size, and in Case 9 where the curve of the pulmonary artery became a little flatter. In these cases, where before ligation no gross degree of abnormality was apparent, little change is to be expected.

Effects of Operation. The young adult is certainly relieved to feel that his disability is cured, and that his heart is normal, although, of course, he does not know his medical prognosis. To be free from the various disadvantages detailed above is obviously a benefit.

Whether there remains any risk of infection on the dimple that I suppose persists at either end of the ligated ductus, one cannot yet say. One must not press the analogy too far, but infection on the pits and excrescences of an atheromatous aorta is very uncommon, and primary infection on the right side of the heart is very rare. The favourite site for infection is where blood passes through a small hole. For instance, organisms attack the patent septum of Maladie de Roger often enough, but not that found in Fallot's tetralogy.

One may hope that the risk of infection after ligation is negligible.

In some children a patent ductus arteriosus seems to retard mental and physical development, and it must be desirable to obviate this.

To leave operation until heart failure has set in, when the patient is probably well into adult life and the procedure less easy and more risky, is surely a mistake. To wait until infection has occurred is dangerous, for although brilliant cures have been effected, they cannot be relied on.

\section{SUMMARY}

Ligation of the patent ductus arteriosus has been performed in thirteen cases. No anxiety arose in any case following operation. One patient, infected before operation, died later. One other patient died of septicæmia which started after nine days normal convalescence. It may possibly have arisen as a result of the operation, but there were no direct evidence of this.

The conclusion is that ligation is a good method of treatment in any patient with patent ductus arteriosus; the sooner after the sixth year, the better.

\section{APPENDIX OF CASE Notes}

Case 1. Male, aged 16. Drayman's apprentice. He was of rather poor physique and somewhat slow mentality. He had lived an ordinary life without symptoms, but had been rejected by the Air Training Corps Board.

A typical murmur was heard above the pulmonary area just after the first sound, extending faintly into diastole. There was no thrill. The pulmonary second sound was loud. The pulmonary artery was enlarged and there was a slight pulsation in the hilar vessels. The heart was not enlarged. B.P. 144/40-135/80. Electrocardiogram (EC.) normal. There was functional albuminuria. Blood urea, 24 mg. per 100 c.c. Specific gravity test and urea clearance were normal.

At operation the ductus was estimated as being about $10 \mathrm{~mm} . \times 6 \mathrm{~mm}$. The thrill over it disappeared at once on pressure, and permanently on ligation.

After operation the pulse rose to 140 , but was down to 80 on the fourth day. The blood urea rose to $41 \mathrm{mg}$. per 100 c.c. on the fourth day, but fell to $22 \mathrm{mg}$. per 100 c.c. on the seventh day. A small local pneumothorax appeared at the left apex and a small hydrothorax at the left base. These cleared up in the following three weeks, breathing exercises being given as soon as possible.

He left hospital eight weeks after operation, having gained $4 \mathrm{lb}$. The ductus murmur had disappeared, though a faint systolic was heard for a time. He seemed to be much more lively towards the end of his stay. At no time was there any anxiety about him and he tolerated the operation well. When seen again three years and nine months later, he was a flight-sergeant in the R.A.F., shortly to undertake operational duties. The skiagram showed no change in the cardiac outline. B.P.120/80, 
Case 2. Female, aged 18. Clerk. She had never had any symptoms, but since the discovery of the lesion at the age of five, had been kept from strenuous activities She was well-built and of normal mentality. She had been referred by a medical board under the Military Training Act.

A typical murmur, occurring late in systole and persisting through diastole, was audible in the second and third left spaces. A thrill was felt. The pulmonary second sound was loud. The heart was not enlarged $(12.25 \mathrm{~cm}$. in diameter) but the pulmonary artery was a little full. B.P. 120/70.

At operation the ductus seemed to be about $10 \mathrm{~mm} . \times 6 \mathrm{~mm}$. The thrill disappeared at once on pressure and ligation. Afterwards the pulse did not rise above 110. A small hydrothorax appeared at the left base. Blood urea on third day, $26 \mathrm{mg}$. per 100 c.c. She was up on the twelfth day and left after five weeks, the fluid having quickly disappeared. Only a faint systolic murmur could be heard in the pulmonary area. The case gave no anxiety at all.

When seen two and a half years later she was very well, and particularly pleased to feel she was normal. The contour of the pulmonary artery was unchanged; the transverse diameter was $11.75 \mathrm{~cm}$. B.P. $110 / 80$.

Case 3. Female, aged 25. Lift attendant. The lesion had been found in childhood and she had lived a somewhat restricted life, with liability to undue dyspnœa. She had been referred under the Military Training Act. She was of normal build and mentality.

The usual typical thrill and murmur were present, with a loud and palpable pulmonary closure. The heart was somewhat enlarged, transverse diameter $13.5 \mathrm{~cm}$., and the shadow of the pulmonary artery was slightly increased. B.P. 120/50, 120/80. EC. normal. Kidney function normal.

The operation (24/9/42) was followed by no complications, and there was but little discomfort. The pulse did not exceed 110, and she left in a month. The murmur had completely disappeared.

Two months later she felt very well, and was pleased to be normal. The transverse diameter of the heart was $12.5 \mathrm{~cm}$. and the shadow of the pulmonary artery was a little smaller. Probably as a result of enemy action, it has been impossible to trace her, for her home has been destroyed.

Case 4. Female, aged 31. Lorry driver. She had always been breathless on anything more than slight exertion, and had never played any games. Lately the dyspnœa and palpitation had been worse, but this was probably mainly due to hypochromic anæmia (66 per cent $\mathrm{Hb}$.).

There was a characteristic low-pitched persistent murmur, with thrill, and some systolic pulsation above the pulmonary area, with a very loud second sound. The pulmonary artery was rather large. The transverse diameter was $12 \cdot 25 \mathrm{~cm}$. B.P. 120/85. Kidney function normal. EC. normal.

The thrill ceased when the ductus was tied. After operation the pulse rose to 120 on one occasion. A small effusion formed in the mid-zone but soon cleared, and she left after a month. A slight systolic murmur persisted.

When seen twenty-six months later she was very well, and free from dyspnœa. The transverse diameter and the curve of the pulmonary artery were unchanged. B.P.120/90. No murmur was heard.

Case 5. Female, aged 10. (Dr. C. Shaw.) A thin, puny child, not robust, weighing $45 \mathrm{lb}$. Mentally very alert and intelligent. She had had no symptoms, except liability to asthma.

There were the typical murmur and thrill of a patent ductus arteriosus, with loud palpable pulmonary closure. The heart appeared to be slightly enlarged. B.P. 110/56-120/70. EC. normal.

Before operation the heart rate was very unstable, varying between 130 and 80 . After operation there was an increase to $\mathbf{1 6 0}$ for a short time; but the rate soon settled and was much steadier than before. The ductus was funnel-shaped, base towards pulmonary artery, and about 7-9 mm. wide and $11 \mathrm{~mm}$. long.

The signs of patent ductus disappeared after ligation, only a faint systolic whiff being audible. A small pneumothorax at the left apex and small effusion at the left base cleared up in a fortnight with the help of breathing exercises, and she left hospital three weeks after operation, having gained nine pounds in weight. The case caused no anxiety for the operation was well tolerated.

Two and a half years later her mother reports that she is very well, growing fast and learning tap dancing. She now weighs $82 \mathrm{lb}$.

Case 6. Female, aged 9. (Dr. W. Sheldon.) Thin asthenic child, weighing $54 \mathrm{lb}$., of normaI mentality, eighth in family. There had been no symptoms, and she had played the usual games.

There were the typical murmur and thrill of patent ductus, with very loud and palpable pulmonary closure. The pulmonary artery was enlarged but not the ventricles. EC. normal. B.P. 120/60.

For a few hours after operation the heart rate was 140 , but it soon settled. There were no complications and she left hospital on the fifteenth day. The murmur had completely disappeared.

When seen two years later she was well. The parents were particularly pleased with her progress at school, where she had recently won a scholarship. Her intelligence quotient rose 21 points five 
months after operation. She had become more lively and active. She now weighed $69 \mathrm{lb}$. B.P. $140 / 60$. Radioscopy showed that the pulmonary artery now had a normal contour.

Case 7. Female, aged 21. (Dr. J. Maxwell.) Well-developed young woman of rather neurotic mentality. Her activities had always been restricted, and latterly she had been too breathless to do much:

There were the harsh continuous murmur and thrill of patent ductus above pulmonary valves; there was no cardiac enlargement, and the contour of the pulmonary artery was normal. B.P. 110/85. EC. normal.

At operation the ductus was found to be short and wide. The next day the murmur had gone, breathing was easy, the pulse did not exceed 100. She left hospital twenty-four days after operation; there were no pulmonary complications.

Six months later she could do more; skiagram of heart unchanged in outline. Nineteen months after operation she had not started work, but that seemed to be due to her cardiac neurosis.

Case 8. Male, aged 6. (Dr. W. Sheldon.) An active child in good condition, weighing $55 \mathrm{lb}$.

Above the pulmonary area there was a characteristic continuous murmur of a patent ductus, with slight systolic pulsation and a loud second sound. There was a slight suggestion of a pulmonary reflux. No thrill was palpable. The heart was not enlarged, but the pulmonary artery showed some enlargement. EC. normal. B.P. 110/65.

After operation the heart rate rose to 130 for a day or so. He was very little affected. Breathing exercises were given and he was up on the seventh day. There were no pulmonary complications. He left after eight weeks in hospital, having gained $4 \mathrm{lb}$. The murmur disappeared at once, but an exocardial click persisted.

When seen eighteen months later the shadow of the pulmonary artery was unchanged, but the closure was no longer palpable. He was very well and had grown a good deal.

Case 9. Male, aged 6. (Dr.W. Sheldon.) A small, dull child, weighing $35 \mathrm{lb}$. There had been dyspnœa on exertion.

Above the pulmonary area there was a continuous murmur of patent ductus. The heart was not enlarged; the curve of the pulmonary artery was slightly increased.

The operation was done under avertin. Afterwards the pulse rose to 130 for two days. There was slight surgical emphysema and some transient collapse at the left base. This soon cleared up with breathing exercises, and he left hospital on the tenth day.

Nine months later his parents wrote saying that he weighed $40 \mathrm{lb}$., and that his breathlessness had gone; and that he seemed much more grown up since the operation and was very quick at school.

Case 10. Male, aged 7. (Mr. J. Hunter.) A small boy, dull and slow and backward mentally, weighing $60 \mathrm{lb}$. A typical murmur was heard, but no thrill was felt; the pulmonary second sound was not particularly loud: there was no pulsation. Heart was not enlarged. B.P. 115/85. EC. normal.

The operation was followed by no complications and he left hospital on the seventeenth day. The murmur had entirely disappeared.

This case is too recent for any subsequent progress to be of interest yet.

Case 11. Female, aged 12. (Dr.W. Sheldon.) Some complaint of breathlessness and palpitation: found she had to stop doing things before the others in the physical training class. A well-built girl, weighing $7 \mathrm{st} .4 \mathrm{lb}$.

The murmur was hardly audible in diastole. There was no thrill. The heart was not enlarged (transverse diameter $11 \mathrm{~cm}$.). B.P. 135/70. EC. normal. Pulmonary artery rather large in skiagram.

At operation the ductus was found to be large. The pulse reached 120 for one day, but soon subsided. A small hydropneumothorax followed, with some infection needing sulphapyridine, but it was quickly controlled. She left hospital on the twenty-fifth day. A year later she was reported to be very well, and had gained $10 \mathrm{lb}$.

Case 12. Female, aged 5. (Dr.W. Sheldon.) A small, thin child, weighing $30 \mathrm{lb}$. Her mentality was normal for the age.

The characteristic thrill and murmur were present, just above the pulmonary area. B.P. 100/55, 100/70. The heart was not enlarged, and the pulmonary contour normal. EC. normal.

After ligation the thrill at once disappeared, and later the murmur was found to have gone. Breathing was easy though the pulse reached 120. No complications occurred; but on the tenth day a high fever started, which was found to be due to staphylococcal septicæmia. Of this she subsequently died, in spite of sulphonamides and penicillin. No post-mortem examination was allowed; the 
source of the infection remained obscure: whether as regards the operation it was "post" or "propter" cannot be said, but such infections not uncommonly arise without apparent cause, and for ten days nothing went amiss.

Case 13. Female, aged 26. This patient came in with infection of a patent ductus arteriosus. This had started about the time of a tooth-extraction two months before. The infection was due to Streptococcus viridans. The usual murmur and thrill were present. B.P. 155/65. The heart was not enlarged.

The ductus was ligated without complications. For a few days the murmur disappeared but later it returned. Infarcts appeared in the lungs, and the signs of an infection of the aortic valves were detected. In spite of courses of sulphonamides she ultimately died. At autopsy it became clear what had happened. The ductus was not effectively closed because it was too full of vegetations. The pulmonary artery and valves were extensively affected, and there were vegetations on the aortic valves. The murmurs that again became audible arose from the imperfectly occluded ductus and later from the diseased pulmonary artery and valves and from the aortic valves.

The fatal ending in this case is an argument in favour of prophylactic ligation. 